\title{
Qualidade da silagem de trigo produzida sob níveis de adubação nitrogenada em dois estádios fenológicos
}

\author{
Quality of wheat silage produced under different levels of nitrogen dressings at two phenological \\ stages
}

Felipe de Lima Wrobel ${ }^{1}$, Mikael Neumann ${ }^{1}$, Guilherme Fernando Mattos Leão ${ }^{2 *}$, Itacir Eloi Sandini ${ }^{1}$,
Mailson Poczynek ${ }^{1}$ \& Fabiano Marafon ${ }^{1}$ ${ }^{1}$ Universidade Estadual do Centro Oeste, Guarapuava, PR, Brasil.

${ }^{2}$ Universidade Federal do Paraná, Curitiba, PR, Brasil. *Autor para correspondência: gfleao@hotmail.com.

Submissão: 18/03/2016 / Aceite: 13/06/2018

\begin{abstract}
RESUMO
O objetivo do trabalho foi avaliar os efeitos de dois níveis de adubação nitrogenada em cobertura (88 kg $\mathrm{ha}^{-1}$ e $148 \mathrm{~kg} \mathrm{ha}^{-1}$ ) na produção de silagem do trigo cultivar BRS Umbu, colhido em dois estádios fenológicos (pré-florescimento e grão farináceo). Foram avaliadas as produções de fitomassa fresca e seca, composição morfológica e bromatológica das silagens. O delineamento experimental foi de blocos ao acaso em esquema fatorial $2 \times 2$, sendo dois níveis de adubação nitrogenada em cobertura e dois estádios de colheita, com quatro repetições. Houve interação $(p<0,05)$ entre os níveis de adubação nitrogenada e os estádios fenológicos de colheita para fibra em detergente neutro (FDN) e fibra em detergente ácido (FDA) da silagem. O trigo cultivado com nível de $88 \mathrm{~kg} \mathrm{~N}$ ha $^{-1}$ e colhido no estádio fenológico grão farináceo apresentou os menores teores de FDN (57,52\%) e FDA (34,62\%)

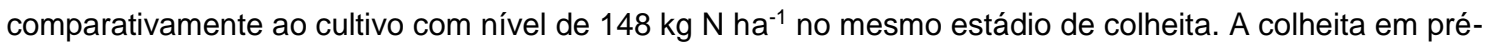
florescimento promoveu maior produção de fitomassa fresca (25.178 contra $20.646 \mathrm{~kg} \mathrm{ha}^{-1}$ ), entretanto, houve maior produção de fitomassa seca no estádio de grão farináceo $\left(9.792\right.$ contra $\left.4.808 \mathrm{~kg} \mathrm{ha}^{-1}\right)$. Os teores de proteína bruta foram maiores na silagem colhida em estádio de pré-florescimento quando comparada a de grão farináceo, com 11,55 e 6,96\%, respectivamente. Na avaliação conjunta dos resultados, é possível concluir que a silagem de trigo colhida em estádio de grão farináceo e com adubação nitrogenada de $88 \mathrm{~kg} \mathrm{ha}^{-1}$ possibilitou os melhores resultados produtivos e nutricionais.
\end{abstract}

PALAVRAS-CHAVE: alimentos conservados, fibra em detergente neutro, grão-farináceo, préflorescimento, proteína bruta.

\begin{abstract}
The objective was to evaluate the effects of two content levels of nitrogen dressing ( $88 \mathrm{~kg} \mathrm{ha}^{-1}$ and $148 \mathrm{~kg}$ $\mathrm{ha}^{-1}$ ) in the wheat silage production of BRS Umbu harvested during two phenological stages (pre-flowering and floury grain). The production of fresh dry phytomass as well as morphological and chemical composition of silages were evaluated. This study used a randomized blocks design with a 2x2 factorial structure, with two content levels of nitrogen dressing and at two different harvest stages, with four replications. There was interaction $(p<0.05)$ between levels of nitrogen dressing and phenological harvest stages for neutral detergent fiber (NDF) and acid detergent fiber (ADF) of silage. The wheat with a level of $88 \mathrm{~kg} \mathrm{~N} \mathrm{ha}^{-1}$ and harvested at the phenological stage of floury grain had the lowest NDF (57.52\%) and ADF (34.62\%), compared to the cultivation with content of $148 \mathrm{~kg} \mathrm{~N} \mathrm{ha}^{-1}$. Harvest during pre-flowering promoted higher production of fresh phytomass (25.178 to $20.646 \mathrm{~kg} \mathrm{ha}^{-1}$ ); however, there was higher production of dry matter in the floury grain stage $\left(9.792\right.$ to $\left.4.808 \mathrm{~kg} \mathrm{ha}^{-1}\right)$. Crude protein was higher in silage harvested during pre-flowering compared to the floury grain stage, with $11.55 \%$ and $6.96 \%$, respectively. Based on joint analysis of the results, wheat silage harvested at the stage of floury grain and with nitrogen dressing of $88 \mathrm{~kg} \mathrm{ha}^{-1}$ had the best production and nutritional outcomes.
\end{abstract}

KEYWORDS: preserved food, neutral detergent fiber, floury grain, pre-flowering, crude protein.

\section{INTRODUÇÃO}

Apesar de silagens de trigo não serem comumente utilizadas (BUMBIERIS JUNIOR et al. 2011), o 
uso de cereais de inverno para produção de silagem gera benefícios para o sistema de produção como a utilização das áreas em pousio durante o inverno para produção de volumosos de qualidade, além de minimizar os riscos do déficit volumoso por variáveis climáticas.

Dentre os alimentos passíveis de conservação, o milho é o mais utilizado por possuir alta densidade energética e alta produção de matéria seca por área. Em contrapartida, os cereais de inverno são caracterizados por possuírem um alto teor de proteína bruta e fibras mais digestíveis em sua composição (FONTANELI et al. 2009). Portanto, um não substitui o outro, mas sim, cada qual pode ter uma função distinta dentro de cada dieta.

No entanto, a qualidade e a produtividade da silagem de trigo dependem do estádio fenológico de colheita, tendo o estádio de pré-florescimento uma maior participação de folhas em relação a colmos, e o estádio de grão farináceo uma alta proporção de amido na sua constituição, o qual atua de forma positiva na fermentação da silagem. Além disso, o avanço dos estádios fenológicos da cultura aumenta a produção de matéria seca por área, além do benefício da alta concentração de amido depositada nos grãos, aumentando o índice calórico do alimento. Porém, ao mesmo passo, com o avançar da maturidade da planta tem-se redução no teor de proteína bruta da mesma em função da diluição provocada pelo aumento dos teores de compostos estruturais como a celulose, hemicelulose e a lignina (VAN SOEST 1994).

Uma forma de minimizar os baixos níveis de proteína bruta provocado pelo avanço do ciclo da cultura, é o incremento nos níveis de nitrogênio comumente aplicados em cobertura, permitindo assim aliar altos valores proteicos e energéticos no material resultante. É sabido que além de ser o principal constituinte das proteínas, o nitrogênio é considerado essencial também para o desenvolvimento das plantas participando da síntese de ácidos nucleicos, hormônios, clorofila e vários outros compostos capazes de otimizar a produtividade das culturas (SANTOS 2004).

Ademais, HASTENPFLUG et al. (2009) asseguram que o nitrogênio aumenta a capacidade de emissão de perfilhos e de estrutura física da planta, o que garante maiores produções de biomassa, tanto verde como seca. TEIXEIRA FILHO et al. (2010), corroboram que os níveis de nitrogênio (N) determinam o potencial produtivo da cultura, onde a elevação dos níveis de $\mathrm{N}$ tende a gerar aumento da produtividade de forragem e grãos, mas que, esses níveis elevados podem causar acamamento da cultura interferindo negativamente na produção (ZAGONEL et al. 2002).

Sendo assim, o objetivo deste trabalho foi avaliar o efeito da colheita em diferentes estádios fenológicos e níveis de adubação nitrogenada em cobertura no trigo BRS Umbu para produção de silagem.

\section{MATERIAL E MÉTODOS}

O experimento foi conduzido nas dependências do Núcleo de Produção Animal (NUPRAN), pertencente a Universidade Estadual do Centro Oeste no município de Guarapuava, PR. Segundo a classificação de Köppen, a região é classificada como Cfb (Subtropical mesotérmico úmido), com verões amenos e inverno moderado, sem estação seca definida e com geadas severas. A precipitação anual média é de $1944 \mathrm{~mm}$, temperatura mínima média anual de $12,7^{\circ} \mathrm{C}$, temperatura máxima média anual de $23,5^{\circ} \mathrm{C}$ e umidade relativa do ar de $77,9 \%$.

A cultura do trigo foi implantada em sistema de plantio direto utilizando o espaçamento entre linhas de $17 \mathrm{~cm}$, profundidade de semeadura de $4 \mathrm{~cm}$ e densidade de semeadura de 220 sementes por $\mathrm{m}^{2}$. A área experimental foi de $160 \mathrm{~m}^{2}$, dividida em 16 parcelas de $10 \mathrm{~m}^{2}$. Para a adubação de base foi utilizado o fertilizante N-P-K na formulação 08-30-20 (N-P $\left.\mathrm{P}_{2} \mathrm{O}_{5}-\mathrm{K}_{2} \mathrm{O}\right)$, na dose de $400 \mathrm{~kg} \mathrm{ha}^{-1}$, respeitando recomendações da Comissão De Fertilidade Do Solo de Santa Catarina e Rio Grande do Sul (CQFS-RS/SC 2004). O material experimental utilizado foi o BRS Umbu (Triticum aestivum L) de característica mútica.

Com relação aos tratamentos, foram considerados dois níveis de adubação nitrogenada de cobertura, 88 ou $148 \mathrm{~kg} \mathrm{ha}^{-1}$ de nitrogênio, aplicados sob a forma de ureia. Já com relação aos estádios fenológicos foram avaliados dois pontos, o pré-florescimento e o estádio de grão farináceo, com pontuação de 10.1 e 11.2 na escala de Feeks-Large, respectivamente (LARGE 1954).

Logo após o corte, foram coletadas amostras da fitomassa para quantificar a produção de fitomassa fresca e seca, além de processar amostras pertinentes à avaliação da composição física da planta onde foram separadas as frações colmo, folha, espiga e folha senescente.

Em seguida, a forragem de cada parcela foi triturada em uma máquina forrageira estacionária com tamanho médio de partículas de $2 \mathrm{~cm}$. O material picado de cada parcela foi armazenado em dois silos experimentais de PVC (Poly Vinyl Choride), com $10 \mathrm{~cm}$ de diâmetro e $45 \mathrm{~cm}$ de comprimento. A compactação da forragem de trigo foi manual com auxílio de um bastão de madeira. Para vedação dos silos foi utilizada lona plástica e o fechamento concluído com fita adesiva. Após 30 dias em ambiente anaeróbico, 
os silos foram abertos e amostras foram coletadas para análise bromatológica.

As amostras coletadas dos tratamentos foram secadas em estufa de ventilação forçada a $50 \stackrel{\circ}{ } \mathrm{C}$ até obtenção de peso constante para a determinação da matéria seca (MS) parcial. Posteriormente cada amostra foi moída em moinho tipo Willey, com peneira de $1 \mathrm{~mm}$.

$\mathrm{Na}$ análise bromatológica, as amostras foram encaminhadas para estufa a $105 \stackrel{\circ}{\circ} \mathrm{C}$ por 4 horas onde se determinou a MS total (SILVA \& QUEIROZ 2009). O nitrogênio total foi determinado pelo método micro Kjeldahl. A matéria mineral (MM) foi determinada por incineração a $550 \stackrel{\circ}{ } \mathrm{C}$ (4 horas), conforme SILVA \& QUEIROZ (2009).

Foram determinados os teores de fibra em detergente neutro (FDN), conforme VAN SOEST et al. (1991), utilizando-se $\alpha$-amilase termoestável, fibra em detergente ácido (FDA) segundo GOERING \& VAN SOEST (1970) e os teores de hemicelulose por diferença (Hemicelulose $=$ FDN - FDA) seguindo metodologia proposta por SILVA \& QUEIROZ (2009).

O delineamento experimental foi blocos ao acaso em esquema fatorial $2 \times 2$, composto por quatro tratamentos com quatro repetições, sendo dois estádios fenológicos de colheita (pré-florescimento e grão farináceo) e dois níveis de adubação nitrogenada de cobertura (88 e $148 \mathrm{~kg} \mathrm{ha}^{-1}$ ). Os dados coletados para cada variável foram submetidos à análise de variância e a diferença entre as médias foram determinadas pelo teste $\mathrm{F}$ a $5 \%$ de probabilidade. Para as variáveis que foram obtidas interações, foram realizadas comparação de médias pelo teste de Tukey a $5 \%$ de probabilidade. As análises estatísticas foram realizadas pelo programa estatístico SAS (1993).

\section{RESULTADOS E DISCUSSÃO}

Os dados relativos à produção de fitomassa fresca e seca encontram-se na Tabela 1. Houve diferença significativa $(p<0,05)$ tanto entre os estádios fenológicos de colheita para produção de fitomassa fresca como também para os níveis de adubação nitrogenada sendo maior no estádio de pré-florescimento e com a adoção de adubação nitrogenada de $148 \mathrm{~kg} \mathrm{ha}^{-1}$. Entretanto, a maior produção de fitomassa seca ocorreu no estádio de grão farináceo.

Tabela 1. Produção de fitomassa fresca e seca de trigo para silagem colhido em diferentes estádios fenológicos e cultivado em níveis de adubação nitrogenada em cobertura.

Table 1. Fresh and dry wheat phytomass production for silage harvested at different phenological stages and at different content levels of nitrogen dressing.

\begin{tabular}{llll}
\hline \multirow{2}{*}{$\begin{array}{l}\text { Nível de adubação nitrogenada } \\
\mathrm{kg} \mathrm{ha}^{-1}\end{array}$} & \multicolumn{2}{c}{ Estádio Fenológico } & \multirow{2}{*}{ Média } \\
\cline { 2 - 3 } & Pré-florescimento & Grão farináceo & \\
88 & Fitomassa fresca $\left(\mathrm{kg} \mathrm{ha}^{-1}\right)$ & & $21.558 \mathrm{~b}$ \\
148 & 23.502 & 19.615 & $24.267 \mathrm{a}$ \\
Média & 26.856 & 21.678 & \\
\hline & $25.178 \mathrm{~A}$ & $20.646 \mathrm{~B}$ & $6.949 \mathrm{~b}$ \\
88 & Fitomassa seca $\left(\mathrm{kg} \mathrm{ha}^{-1}\right)$ & & $7.652 \mathrm{a}$ \\
148 & 4.597 & 9.301 & \\
\hline Média & 5.020 & 10.284 & $9.792 \mathrm{~A}$ \\
\hline
\end{tabular}

Médias seguidas de letras maiúsculas na linha ou minúsculas na coluna, diferem entre si pelo teste a $5 \%$ de probabilidade.

A justificativa para o incremento de matéria seca ao longo da maturidade é explicada pelo processo fisiológico da planta. Neste caso, a planta aumenta o teor de matéria seca pelo processo de florescimento e início de atividade reprodutiva que acaba por garantir maior participação de grãos (WEINBERG et al. 2010). Dessa forma, BECK et al. (2009) constataram que houve aumento em função do avanço dos estádios de maturação do trigo, com produções de $2.781 \mathrm{~kg} \mathrm{ha}^{-1}$ e $6.261 \mathrm{~kg} \mathrm{ha}^{-1}$ com $21,5 \%$ de matéria seca no florescimento e $46,7 \%$ em grão farináceo, respectivamente, salientando a explicação fisiológica e corroborando com os dados do presente estudo. Na literatura específica para o trigo, especialmente para a variedade Umbu, destaca-se os achados por CARLETTO (2013), o qual observaram produções de fitomassa seca em consonância a este trabalho.

Já com relação à diferença estatística $(p<0,05)$ pertinente a adubação nitrogenada, houveram maiores resultados tanto para fitomassa fresca como fitomassa seca para o tratamento com maior inclusão de nitrogênio. TAIZ \& ZIEGER (2009), explicam que o trigo possui metabolismo C3 a sua demanda por N é 
muito elevada e de particular importância para assimilação de $\mathrm{CO}_{2}$, o que interfere consequentemente 0 ganho da fitomassa. Ademais, NABINGER \& PONTES (2001) e MALAVOLTA (2006) explicam que o nitrogênio é um dos principais nutrientes que controla os processos de desenvolvimento das plantas, fixando mais carbono e aumentando a fitomassa. Logo, com maiores inclusões de nitrogênio maiores produções são esperadas.

Com relação a maior produção de fitomassa seca, esta pode ser explicada pelo aumento na produção de folhas proporcionado pelo incremento nos níveis de nitrogênio. CRUZ et al. (2007) explicam que esse aumento no número de folhas associado ao seu tamanho contribui para o aumento da área foliar, interferindo na interceptação da energia solar pelas folhas, potencializando a assimilação de carbono o qual pode contribuir significativamente para aumentar o acúmulo de massa seca pelas plantas.

Como exemplo na literatura, PIETRO-SOUZA et al. (2013) analisando a parte aérea do trigo, obteve máxima produção de biomassa seca com dose de nitrogênio de $165 \mathrm{~kg} \mathrm{ha}^{-1}$, semelhante ao maior nível de adubação utilizado no experimento.

De acordo com a Tabela 2, houve maior teor de matéria seca $(p<0,05)$ no estádio fenológico de grão farináceo para o componente colmo (41,90 contra 17,90\%), folhas senescentes $(76,87$ contra $30,46 \%)$, folhas verdes $(40,95$ contra $21,55 \%)$ e espigas $(54,41$ contra $19,50 \%)$ quando comparados ao estádio de pré-florescimento. Já com relação à adubação nitrogenada, não houve diferença estatística $(p>0,05)$ entre os tratamentos.

Tabela 2. Teores de matéria seca da planta e dos componentes físicos do trigo para silagem colhido em diferentes estádios fenológicos e cultivado em níveis de adubação nitrogenada em cobertura.

Table 2. Dry matter content and physical components of wheat for silage harvested at different phenological stages and at different content levels of nitrogen dressing.

\begin{tabular}{|c|c|c|c|}
\hline \multirow{2}{*}{$\begin{array}{l}\text { Nível de adubação nitrogenada } \\
\mathrm{kg} \mathrm{ha}^{-1}\end{array}$} & \multicolumn{2}{|c|}{ Estádio Fenológico } & \multirow{2}{*}{ Média } \\
\hline & Pré-florescimento & Grão farináceo & \\
\hline & MS do Colmo(\%) & & \\
\hline 88 & 18,63 & 42,25 & $30,44 \mathrm{a}$ \\
\hline 148 & 17,18 & 41,55 & 29,36 a \\
\hline \multirow[t]{2}{*}{ Média } & $17,90 \mathrm{~B}$ & $41,90 \mathrm{~A}$ & \\
\hline & \multicolumn{2}{|c|}{ MS da Folha senescente(\%) } & \\
\hline 88 & 31,80 & 76,25 & $54,02 \mathrm{a}$ \\
\hline 148 & 29,13 & 77,50 & $53,31 \mathrm{a}$ \\
\hline \multirow[t]{2}{*}{ Média } & $30,46 \mathrm{~B}$ & $76,87 \mathrm{~A}$ & \\
\hline & \multicolumn{2}{|c|}{ MS da Folha verde(\%) } & \\
\hline 88 & 21,85 & 42,85 & $32,35 \mathrm{a}$ \\
\hline 148 & 21,25 & 39,05 & $30,15 \mathrm{a}$ \\
\hline \multirow[t]{2}{*}{ Média } & $21,55 \mathrm{~B}$ & $40,95 \mathrm{~A}$ & \\
\hline & \multicolumn{2}{|l|}{ MS da Espiga(\%) } & \\
\hline 88 & 20,60 & 54,60 & $37,60 \mathrm{a}$ \\
\hline 148 & 18,40 & 54,23 & $36,31 \mathrm{a}$ \\
\hline \multirow[t]{2}{*}{ Média } & $19,50 \mathrm{~B}$ & $54,41 \mathrm{~A}$ & \\
\hline & \multicolumn{2}{|c|}{ MS da Planta inteira(\%) } & \\
\hline 88 & 19,56 & 47,40 & $33,48 \mathrm{a}$ \\
\hline 148 & 18,69 & 47,55 & $33,12 \mathrm{a}$ \\
\hline Média & $19,12 \mathrm{~B}$ & $47,47 \mathrm{~A}$ & \\
\hline
\end{tabular}

Médias seguidas de letras maiúsculas na linha ou minúsculas na coluna, diferem entre si pelo teste a $5 \%$ de probabilidade.

Esse aumento de matéria seca nos grãos fica evidente no percentual de matéria seca da espiga, onde houve um aumento com o avanço dos estádios fenológicos de pré-florescimento para grão farináceo. O componente com maior aumento no teor de MS foi a folha senescente, obtendo aumento de $152,36 \%$ no teor de MS com avanço dos estádios fenológicos de pré-florescimento para grão farináceo.

Como supracitado, WEINBERG et al. (2010) justificam que no decorrer do ciclo da cultura ocorreu aumento no teor de MS da planta gerado pelo aumento da participação de grãos na forragem destinada a silagem. Esta mudança no teor de MS tem implicação não somente na participação dos componentes da 
forrageira como também no valor nutritivo da silagem (OLIVEIRA 2014).

A colheita do material com maiores percentuais de MS é justificada pela influência que este fator possui no processo fermentativo da ensilagem. Materiais colhidos com baixos teores de MS geram impactos negativos sobre a qualidade final do material, elevando a lixiviação de nutrientes através da maior produção de efluentes e a ocorrência de fermentações secundárias pela ação de microrganismos, em especial os pertencentes ao gênero Clostridia (KUNG JR. et al. 2003).

Desta forma, FONTANELI et al. (2009) recomendam corte do trigo para silagem em estádio fenológico de grão massa mole tendendo a grão farináceo. Caso contrário os autores sustentam a necessidade do emurchecimento caso o cereal de inverno seja colhido na fase de florescimento. Não obstante, esta taxa de emurchecimento varia de acordo com as características estruturais das forragens, como, por exemplo, a espessura do colmo e proporção folha/colmo, devendo ser levados em consideração para a definição do tempo de secagem e teor final de MS (NERES et al. 2011).

No tocante a inversão da participação dos componentes da planta folhas verdes e espiga nos estádios fenológicos pré-florescimento para grão farináceo, este pode ser explicado pela alteração na relação fonte-dreno que ocorre no decorrer do ciclo da cultura. Segundo TAIZ \& ZEIGER (2009), o transporte de assimilados ocorre da fonte para o dreno sendo que todos os órgãos da planta funcionam como dreno em alguma fase do ciclo. A conversão da folha de dreno para fonte é gradativa sendo que a exportação de carboidratos se inicia antes que a importação tenha cessado. O potencial produtivo da cultura está relacionado então, com a capacidade da planta de produzir, translocar e estocar assimilados nos grãos (SLEEPER \& POELMAN 2006).

$\mathrm{Na}$ Tabela 3 estão representados a participação dos componentes físicos na matéria seca da planta de trigo para a ensilagem. Pode-se observar que os teores de colmo e folha senescente não obtiveram diferença significativa $(p>0,05)$ tanto com relação ao avanço da maturidade como também com a adoção de diferentes níveis de adubação nitrogenada.

Tabela 3. Participação dos componentes físicos na matéria seca (MS) da planta de trigo para silagem colhido em diferentes estádios fenológicos e cultivado em níveis de adubação nitrogenada em cobertura.

Table 3. Participation of physical components in the dry matter (DM) of wheat for silage harvested at different phenological stages and fertilized at different content levels of nitrogen dressing.

\begin{tabular}{|c|c|c|c|}
\hline \multirow{2}{*}{$\begin{array}{l}\text { Nível de adubação nitrogenada } \\
\mathrm{kg} \mathrm{ha}^{-1}\end{array}$} & \multicolumn{2}{|c|}{ Estádio Fenológico } & \multirow{2}{*}{ Média } \\
\hline & Pré-florescimento & Grão farináceo & \\
\hline & Número de colmos & & \\
\hline 88 & 688,75 & 682,75 & $685,75 b$ \\
\hline 148 & 751,25 & 752,75 & $752,00 \mathrm{a}$ \\
\hline \multirow[t]{2}{*}{ Média } & $720,00 \mathrm{~A}$ & $717,75 \mathrm{~A}$ & \\
\hline & Colmo(\% da MS) & & \\
\hline 88 & 41,4 & 36,0 & $38,7 \mathrm{a}$ \\
\hline 148 & 39,6 & 36,3 & $37,9 \mathrm{a}$ \\
\hline \multirow[t]{2}{*}{ Média } & $40,5 \mathrm{~A}$ & $36,1 \mathrm{~A}$ & \\
\hline & Folha senescente & & \\
\hline 88 & 4,6 & 4,3 & $4,4 \mathrm{a}$ \\
\hline 148 & 7,0 & 4,5 & $5,7 \mathrm{a}$ \\
\hline \multirow[t]{2}{*}{ Média } & $5,8 \mathrm{~A}$ & $4,4 \mathrm{~A}$ & \\
\hline & Folha verde(\% da & & \\
\hline 88 & 38,0 & 11,8 & $24,9 \mathrm{a}$ \\
\hline 148 & 39,2 & 11,8 & $25,5 \mathrm{a}$ \\
\hline \multirow[t]{2}{*}{ Média } & $38,6 \mathrm{~A}$ & $11,8 \mathrm{~B}$ & \\
\hline & Espiga (\% da MS) & & \\
\hline 88 & 16,0 & 47,5 & $31,7 \mathrm{a}$ \\
\hline 148 & 14,2 & 47,5 & 30,8 a \\
\hline Média & $15,1 \mathrm{~B}$ & $47,5 \mathrm{~A}$ & \\
\hline
\end{tabular}

Médias seguidas de letras maiúsculas na linha ou minúsculas na coluna, diferem entre si pelo teste a $5 \%$ de probabilidade. 
Entretanto, nota-se que a participação de folhas verdes reduziu enquanto que a participação de espiga aumentou com o decorrer do avanço dos estádios fenológicos. Tal ponto reforça a justificativa explicada anteriormente, na qual a relação fonte/dreno é mudada passando a formação de grãos ser prioridade na planta de trigo com o avanço da maturidade. Outro ponto notável foi a influência da adubação nitrogenada sobre o número de colmos por metro quadrado. Com o aumento dos níveis de adubação houve aumento significativo $(p<0,05)$ na quantidade de colmos. Esse aumento também refletiu na qualidade nutricional, representado na tabela 4.

Tabela 4. Teores de matéria mineral (MM), fibra detergente neutro (FDN), fibra em detergente ácido (FDA), proteína bruta (PB), hemicelulose (HEM) da silagem de trigo colhido em diferentes estádios fenológicos e cultivado em níveis de adubação nitrogenada em cobertura.

Table 4. Contents of mineral matter (MM), neutral detergent fiber (NDF), acid detergent fiber (ADF), crude protein (CP) and hemicellulose (HEM) from wheat silage harvested at different phenological stages and at different content levels of nitrogen dressing.

\begin{tabular}{|c|c|c|c|}
\hline \multirow{2}{*}{$\begin{array}{l}\text { Nível de adubação nitrogenada } \\
\mathrm{kg} \mathrm{ha}^{-1}\end{array}$} & \multicolumn{2}{|c|}{ Estádio Fenológico } & \multirow{2}{*}{ Média } \\
\hline & Pré-florescimento & Grão farináceo & \\
\hline & $\mathrm{MM}(\%$ da MS) & & \\
\hline 88 & 4,32 & 2,39 & $3,35 a$ \\
\hline 148 & 4,84 & 2,51 & $3,67 \mathrm{a}$ \\
\hline \multirow[t]{2}{*}{ Média } & $4,58 \mathrm{~A}$ & $2,45 \mathrm{~B}$ & \\
\hline & FDN (\% da MS) & & \\
\hline 88 & $68,22 \mathrm{a}$ & $57,52 \mathrm{~b}$ & 62,87 \\
\hline 148 & 66,39 a & 64,63 a & 65,51 \\
\hline \multirow[t]{2}{*}{ Média } & $67,31 \mathrm{~A}$ & $61,07 \mathrm{~A}$ & \\
\hline & FDA (\% da MS) & & \\
\hline 88 & $44,03 \mathrm{a}$ & $34,62 \mathrm{~b}$ & 39,32 \\
\hline 148 & $44,21 \mathrm{a}$ & 43,58 a & 43,89 \\
\hline \multirow[t]{2}{*}{ Média } & $44,12 \mathrm{~A}$ & $39,1 \mathrm{~A}$ & \\
\hline & PB (\% da MS) & & \\
\hline 88 & 10,99 & 6,88 & 8,93 a \\
\hline 148 & 12,10 & 7,05 & $9,57 \mathrm{a}$ \\
\hline \multirow[t]{2}{*}{ Média } & $11,55 \mathrm{~A}$ & $6,96 \mathrm{~B}$ & \\
\hline & HEM (\% da MS) & & \\
\hline 88 & 24,19 & 22,90 & $23,54 \mathrm{a}$ \\
\hline 148 & 22,18 & 21,04 & $21,61 \mathrm{a}$ \\
\hline Média & $23,18 \mathrm{~A}$ & $21,97 \mathrm{~A}$ & \\
\hline
\end{tabular}

Conforme Tabela 4, houve diferença estatística $(p<0,05)$ para a MM, FDN, FDA e PB. A fração hemicelulose (HEM) não possuiu diferença significativa $(p>0,05)$ com relação à avaliação dos estádios fenológicos. Em consonância, a adubação nitrogenada não apresentou efeitos significativos também para os teores qualitativos avaliados. Entretanto, foi observada interação significativa $(p<0,05)$ entre os níveis de adubação nitrogenada e os estádios fenológicos de colheita para FDN e FDA da silagem.

O trigo cultivado com nível de adubação nitrogenada $88 \mathrm{~kg} \mathrm{ha}^{-1}$ e colhido no estádio fenológico grão farináceo apresentou os menores teores de FDN (57,52\%) e FDA (34,62\%) comparativamente ao cultivo com nível de adubação nitrogenada $148 \mathrm{~kg} \mathrm{ha}^{-1}$ no mesmo estádio de colheita $(64,63 \%$ e 43,58\%, respectivamente) e este não diferiu $(p>0,05)$ do cultivo com nível de adubação nitrogenada $88 \mathrm{~kg} \mathrm{ha}^{-1}$ (68,22\% e 44,03\%, respectivamente) e $148 \mathrm{~kg} \mathrm{ha}^{-1}$ (66,39\% e $44,21 \%$, respectivamente) para colheita no estádio fenológico de pré-florescimento.

O teor de matéria mineral foi superior no estádio fenológico de pré-florescimento $(4,58 \%)$ quando comparado ao estádio de grão farináceo $(2,45 \%)$, sendo essa redução da matéria mineral decorrente do aumento da idade das plantas (HAAG 1984). A redução nos teores de minerais nas plantas é devido a sua diluição em relação à matéria seca acumulada com avanço do ciclo da cultura (GOMIDE 1976). A redução 
na relação colmo/folha com o transcorrer dos estádios fenológicos, senescência foliar (WILSON \& MANNETJE 1978), absorção mineral e sua redistribuição entre os órgãos da planta são fatores que reduzem a concentração dos minerais na planta.

Para o teor de proteína bruta, este foi superior no estádio fenológico pré-florescimento em relação ao estádio grão farináceo (11,55 contra 6,96\%). Com o avanço no estádio de maturação fisiológica de cereais de inverno, ocorreu decréscimo nos teores de PB (COBLENTZ \& WALGENBACH 2010).

Esse fato é explicado por TAIZ \& ZEIGER (2009), onde plantas em crescimento, principalmente em área foliar, possuem altos teores de $\mathrm{N}$ nesses órgãos e com o avanço dos estádios fenológicos ocorrem aumentos das partes estruturais com menor proporção de nitrogênio e consequente declínio na produção de biomassa e diluição do nitrogênio na planta. A fixação do nitrogênio nas estruturas da parede celular (VAN SOEST 1994) e o aumento de folhas senescentes também explicam a redução da proteína bruta.

Para silagens de trigo colhidas nos estádios de emborrachamento, grão leitoso e grão massa dura, foram encontrados os teores de proteína bruta na MS de 17,7\%, 13,0\% e 10,2\% respectivamente (FONTANELI \& FONTANELI 2009). CARLETTO (2013) e OLIVEIRA (2014) obtiveram com a cultivar BRS Umbu teores de PB de 7,49\% e 9,79\% colhidos em estádio de grão farináceos. Os mesmos autores encontraram teores de MM de 4,89 e 3,86\%, respectivamente. O efeito na redução de teores de MM com incremento de doses de $\mathrm{N}$ foi observado por ZAMARCHI (2013) em silagem de aveia.

Os teores de hemicelulose não foram influenciados $(p>0,05)$ pelos estádios fenológicos de préflorescimento e grão farináceo (23,18 e 21,97\%, respectivamente). Os valores encontrados foram semelhantes aos obtidos por MEINERZ et al. (2011), que obtiveram 22,78\% na matéria seca para a cultivar BRS Umbu em avaliação onde foi simulado o pastejo por animais antes de ser ensilado.

A percentagem de matéria seca dos componentes e a participação dos componentes na planta não variaram no estádio de grão farináceo e entre os níveis de $\mathrm{N}$ aplicado. Outro fato que poderia explicar a redução da FDN e FDA seria o aumento da participação de grãos na fase de grão farináceo levando a diluição das variáveis citadas. Além disso, convenciona-se que a ensilagem em estádios mais maduros pode refletir em uma hidrólise da fração celulose, o que contribuiria para o pool de carboidratos no processo fermentativo (ROOKE \& HATFIELD 2003).

No entanto, em outros trabalhos isto não é tão evidente. BECK et al. (2009) e DAVID et al. (2010) não observaram redução do teor de FDN com o avanço do estádio fenológico do trigo. Estas respostas são justificadas por BUMBIERIS JÚNIOR et al. (2011b) como sendo decorrentes de diferenças nas participações dos constituintes da planta, principalmente grãos, disponibilidade hídrica, estação de crescimento e taxas de secagens distintas entre regiões de clima quente e temperado.

\section{CONCLUSÃO}

A silagem de trigo colhida em estádio de grão farináceo aliada a adubação de $88 \mathrm{~kg} \mathrm{ha}^{-1}$ é superior em termos de desempenho, apresenta ótimo teor de matéria seca e melhor qualidade nutricional.

\section{REFERÊNCIAS}

BECK PA et al. 2009. Effect of wheat forage maturity and preservation method on forage chemical composition and performance of growing calves fed mixed diets. Journal of Animal Science 87: 4133-4142.

BUMBIERIS JUNIOR VH et al. 2011. Use of winter cultures for forage conservation. In: DANIEL JLP et al. Forage quality and conservation. II International symposium on forage quality and conservation. Anais... Piracicaba: FEALQ. p. 65-83.

CARLETTO R. 2013. Características agronômicas e forrageiras de trigo duplo propósito submetido a sistemas de corte na cv. brs umbu. Dissertação (Mestrado em Agronomia). Guarapuava: UNICENTRO. 92p.

COBLENTZ WK \& WALGENBACH RP. 2010. Fall growth, nutritive value, and estimation of total digestible nutrients for cereal-grain forages in the north-central United States. Journal of Animal Science 88: 383-399.

CQFS RS/SC. 2004. Comissão de Química e Fertilidade do Solo. Manual de adubação e calagem para os Estados do Rio Grande do Sul e de Santa Catarina. 10.ed. Porto Alegre: SBCS - Núcleo Regional Sul/UFRGS. 400p.

CRUZ JL et al. 2007. Níveis de nitrogênio e a taxa fotossintética do mamoeiro "Golden". Ciência Rural 37: 64-71.

DAVID DB et al. 2010. Nutritional value of black and white oat cultivars ensiled in two phenological stages. Revista Brasileira de Zootecnia 39: 1409-1417.

FONTANELI RS \& FONTANELI RS. 2009. Silagem de cereais de inverno. In: FONTANELI RS et al. Forrageiras para integração lavoura-pecuária-floresta na região sul-brasileira. Passo Fundo: EMBRAPA TRIGO. 329p.

FONTANELI RS et al. 2009. Rendimento e valor nutritivo de cereais de inverno de duplo propósito: forragem verde e silagem ou grãos. Revista Brasileira de Zootecnia 38: 2116-2120.

GOERING HK \& VAN SOEST PJ. 1970. Forage fiber analysis: apparatus reagents, procedures and some applications. Washington: Agricultural Handbook. 379p.

GOMIDE JA. 1976. Composição mineral de gramíneas e leguminosas forrageiras tropicais. In: Simpósio latino- 
Wrobel et al.

americano sobre pesquisa em nutrição mineral de ruminantes e pastagens. Anais... Belo Horizonte: EPAMIG. p.2033.

HAAG HP. 1984. Nutrição mineral de forrageiras no Brasil. Campinas: Fundação Cargill. 152p.

HASTENPFLUG M. 2009. Desempenho de cultivares de trigo duplo propósito sob doses de adubação nitrogenada e regime de cortes. Dissertação (Mestrado em agronomia - produção vegetal). Pato Branco: UTFPR. 65p.

KUNG JÚNIOR L et al. 2003. Silage additives. In: BUXTON DR et al. Silage science and technology. Madison: American Society of Agronomy; Crop Science Society of America; Soil Science Society of America. p. 305-360.

LARGE EC. 1954. Growth stages in cereals illustration of the Feeks scales. Plant Pathology 3: 128-129.

MALAVOLTA E. 2006. Manual de nutrição de plantas. São Paulo: Agronômica Ceres. 638p.

MEINERZ GR et al. 2011. Silagem de cereais de inverno submetidos ao manejo de duplo propósito. Revista Brasileira de Zootecnia 40: 2097-2104.

NABINGER C \& PONTES LS. 2001. Morfogênese de plantas forrageiras e estrutura do pasto. In: Reunião anual da sociedade brasileira de zootecnia. Anais...Piracicaba: SBZ. p. 755-771.

NERES MA et al. 2011. Production of tifton 85 hay overseeded with white oats or ryegrass. Revista Brasileira de Zootecnia 40: 1638-1644.

OLIVEIRA MR. 2014. Qualidade de silagens de trigo e milho e desempenho de novilhos confinados. Tese (Doutorado em Zootecnia). Maringá: UEM. 75p.

PIETRO-SOUZA W et al. 2013. Desenvolvimento inicial de trigo sob doses de nitrogênio em Latossolo Vermelho de Cerrado. Revista Brasileira de Engenharia Agrícola e Ambiental 17: 575-580.

ROOKE JA \& HATFIELD RD. 2003. Biochemistry of ensiling. In: Silage Science and Technology. Madison: American Society of Agronomy; Crop Science Society of America; Soil Science Society of America. p. 95-135.

SANTOS PM. 2004. Aspectos fisiológicos e metabólicos da nutrição nitrogenada de plantas forrageiras. In: Simpósio sobre manejo da pastagem. Anais... Piracicaba: FEALQ. p. 139-151.

SAS INSTITUTE. 1993. SAS/STAT. User's guide statistics. 4.ed. Version 6. Cary, North Caroline 2. 943p.

SILVA DJ \& QUEIROZ AC. 2009. Análise de Alimentos, métodos químicos e biológicos. 3a‥ ed. 4aimpressão. Viçosa: UFV. 235p.

SLEEPER DA \& POEHLMAN JM. 2006. Breeding field crops. 5.ed. Ames: Blackwell Pub lowa, 424p.

TAIZ L \& ZEIGER E. 2009. Fisiologia vegetal. 4.ed. Porto Alegre: Artmed. 848p.

TEIXEIRA FILHO MCMT et al. 2010. Doses, fontes e épocas de aplicação de nitrogênio em trigo irrigado em plantio direto. Pesquisa Agropecuária Brasileira 45: 797-804.

VAN SOEST PJ. 1994. Nutritional ecology of the ruminant. 2.ed. New York: Cornell University Press. 476p.

VAN SOEST PJ et al. 1991. Methods for dietary fiber, neutral detergent fiber, and nonstarch polysaccharides in relation to animal nutrition. Journal of dairy Science 74: 3583-3597.

WEINBERG ZG et al. 2010. Effects of stage of maturity at harvest, wilting and LAB inoculant on aerobic stability of wheat silages. Animal Feed Science and Technology 158: 29-35.

WILSON JR \& MANNETJE L. 1978. Senescence, digestibility and carbohydrate content of Buffel grass and Green Panic leaves in swards. Australian Journal of Agricultural Research 29: 503-516.

ZAGONEL $J$ et al. 2002. Doses de nitrogênio e densidades de plantas com e sem um regulador de crescimento afetando o trigo, cultivar OR 1. Ciência Rural 32: 25-29.

ZAMARCHI G. 2013. Composição bromatológica de silagem de aveia submetida à adubação nitrogenada e estádios fenológicos de ensilagem. Dissertação (Mestrado em Zootecnia). Dois Vizinhos: UTFPR. 63p. 